\title{
Apresiasi skala kepekaan humor pada etnis Jawa, Madura dan Sunda
}

\author{
Unggul Haryanto Nur Utomo ${ }^{\mathrm{a}, 1^{*}}$ \\ aFakultas Psikologi, Universitas Ahmad Dahlan, Yogyakarta \\ *1.unggul.utomo@psy.uad.ac.id \\ Correspondent Author
}

KATAKUNCI

apresiasi;

budaya;

skala kepekaan humor

\section{ABSTRAK}

Penelitian tentang humor adalah penelitian yang berkaitan dengan fenomena budaya perilaku individu, dan perbedaan antar budaya dapat menyebabkan respon dari tiap individu berkemungkinan berbeda. Oleh karena itu, tujuan dari penelitian ini adalah untuk mengkaji validitas dan reliabilitas alat ukur Skala Kepekaan Humor (SKH) melalui apresiasi etnis Jawa, Madura dan Sunda. Metode yang digunakan pada penelitian ini metode kuantitatif. Pengujian terhadap Skala Kepekaan Humor (SKH) ini melibatkan variabel jenis kelamin dan variabel etnis. Sebanyak 300 subjek dipilih menggunakan teknik stratified quota random sampling dari 615 mahasiswa-mahasiswi berlatar belakang etnis Jawa, Madura dan Sunda. Perbedaan apresiasi antar jenis kelamin dan antar etnis terhadap SKH diuji menggunakan Anava Dua Jalur. Hasil penelitian menunjukan SKH memiliki koefisien reliabilitas alpha sebesar 0,961 dengan tingkat mortalitas aitem $0 \%$. Indeks daya diskriminasi aitem (rit) berkisar 0,380 sampai 0,578. Tidak ada interaksi antara variabel etnis dan variabel jenis kelamin dalam mengapresiasi SKH $(\mathrm{F}=2,875 ; \mathrm{p}>0,05)$, antar etnis menunjukkan perbedaan apresiasi terhadap SKH $(F=4,825 ; p<0,05)$, sedangkan antara laki-laki dan perempuan menunjukkan apresiasi yang relatif setara terhadap SKH $(F=1,899 ; p>0,05)$, yaitu cukup lucu. Pengaruh variabel etnis terhadap apresiasi SKH tidak bergantung pada jenis kelamin. Penelitian menyimpulkan bahwa SKH valid dan reliabel sebagai alat ukur kepekaan humor. SKH juga memiliki data empiris yang mendukungnya menjadi tes yang adil budaya (culture fair) Indonesia, sehingga SKH dapat digunakan menjadi salah satu alat ukur kepekaan humor pada kalangan yang lebih luas.

\section{Appreciation of humor sensitivity scale on Javanese, Madurese and Sundanese ethnics}

Research on humor is research that deals with the cultural phenomenon of individual behavior, and differences between cultures can cause the response of each individual to be different. Therefore, the aim of this study is to examine the validity and reliability of the Humor Sensitivity Scale (SKH) measurement instrument through appreciation of Javanese, Madurese and Sundanese ethnicities. The method used in this research is quantitative method. Testing of the Humor Sensitivity Scale (SKH) involves gender and ethnic variables. A total of 300 subjects were selected using a stratified quota random sampling technique from 615 students with Javanese, Madurese and Sundanese ethnic backgrounds. Differences in appreciation between sexes and between ethnicities 
towards SKH were tested using Two-Way Anava. The results showed that SKH had an alpha reliability coefficient of 0.961 with an item mortality rate of $0 \%$. The item discrimination power index (rit) ranges from 0.380 to 0.578 . There was no interaction between ethnic variables and gender variables in appreciating SKH ( $F=2.875 ; p>0.05)$, between ethnic groups showed differences in appreciation of $S K H(F=4.825 ; p$ $<0.05)$, while between men and women showed relatively equal appreciation towards SKH ( $F=1.899 ; p>0.05)$, which is quite funny. The effect of ethnic variables on SKH appreciation does not depend on gender. The study concluded that SKH is valid and reliable as a measure of humor sensitivity. SKH also has empirical data that supports it to be a fair test of Indonesian culture, so that SKH can be used as a measure of humor sensitivity in a wider circle.

This is an open-access article under the CC-BY-SA license.

\section{Pendahuluan}

Para psikolog dan psikiater internasional mengakui tentang adanya potensi humor, bahwa humor dapat membangun dan menjalin hubungan yang lebih terbuka dan akrab antara ahli terapi dan kliennya; humor dapat dijadikan sebagai media untuk menyalurkan dorongan-dorongan dasar (seperti libido, emosi negatif) dengan cara yang dapat diterima oleh masyarakat; dapat merangsang seseorang meningkatkan kreativitas dengan melihat suatu masalah dari sisi kelucuannya; membuat rasa cemas dan tegang menjadi lebih ringan (Bastaman, 2007). Hasil penelitian menunjukan bahwa humor secara signifikan meningkatkan pengetahuan dan pemahaman dalam konteks pembelajaran (Hackathorn, Garczynski, Blankmeyer, Tennial \& Solomon, 2012). Humor tidak hanya meningkatkan pemahaman tetapi juga mengurangi resistensi (Borcherdt, 2002). Studi yang dilakukan oleh Garner (2006) menemukan bahwa humor di bidang pendidikan tidak hanya meningkatkan hasil belajar mahasiswa tetapi juga peringkat instruktur (pengajar) meningkat lebih positif.

Sampai saat ini pengembangan alat ukur kepekaan humor masih didominasi oleh ilmuwan dari Amerika dan Eropa (Utomo \& Diponegoro, 2017), antara lain yaitu seperti Situational Humor Responses Questionnaire (SHRQ) yang disusun oleh Martin dan Lefcourt, (1984); Coping Humor Scale (CHS) yang sebelumnya juga disusun oleh Martin dan Lefcourt, (1983); Sense of Humor Questionnaire (SHQ) (Svebak, dalam Martin \& Lefcourt, 1983); Mindess (dalam Nilsen, 1993) menyusun alat tes untuk mengukur kematangan terhadap humor; Thorson dan Powell (1996) menyusun Multidimensional Sense of Humor Scale (MSHS); McGhee dan Panoutsopoulou (1990) menggunakan stimulus humor berupa satu buklet berisi empat gambar kartun dan empat lelucon; Levine dan Redlich (dalam Levine, 1956) menggunakan gambar kartun yang diambil dari majalah untuk melihat respon subjek terhadap humor; Eysenck dan Wilson (1982) menyusun alat kepekaan terhadap humor berisi 32 gambar kartun. Sementara Skala Kepekaan Humor (SKH) adalah salah satu alat ukur asli Indonesia yang dikembangkan oleh Hasanat dan Subandi pada tahun 1998 bertujuan untuk mengukur apresiasi terhadap materi humor (conformist sense), versi A dan B masing-masing berisikan 38 aitem figural (jumlah keseluruhan 76 aitem) berupa gambar-gambar kartun karya beberapa kartunis Indonesia.

Analisis faktor eksploratori terhadap SKH dalam penelitian Utomo (2006) menghasilkan empat komponen yaitu kekerasan, kekesalan, parodi dan joke. Kesimpulan hasil penelitian Utomo (2006) diantaranya bahwa SKH versi A-B (digabung maupun secara terpisah) reliabel sebagai alat ukur apresiasi terhadap humor pada kelompok subjek mahasiswa; SKH versi A-B terdiri dari empat faktor/komponen/kategori yaitu kekerasan, kekesalan, parodi dan 
kreativitas (total muatan faktor sebesar 55\%); SKH versi A-B adalah alat ukur kepekaan humor yang valid karena berisi aitem bermuatan humor pada taraf cukup lucu; SKH versi A-B adalah alat ukur yang secara umum terbuka bagi jenis kelamin (tidak rawan bias gender). Penelitian selanjutnya terhadap SKH dilakukan dalam skripsi beberapa mahasiswa di bawah bimbingan peneliti yang difokuskan pada uji validitas dan reliabilitas SKH pada mahasiswa etnis tertentu, yaitu pada 200 mahasiswa etnis Bugis (Abdullah, 2014), 211 mahasiswa etnis Jawa (Triyantoro, 2014), 200 mahasiswa etnis Madura (Yusnita, 2014), 160 mahasiswa etnis Sambas (Susanti, 2014), 204 mahasiswa etnis Sasak (Parianti, 2014) dan 204 mahasiswa etnis Sunda (Kusumasakti, 2014). Keenam skripsi dengan subjek mahasiswa yang berbedabeda latar belakang etnis tersebut menunjukkan hasil yang sama yaitu SKH versi A-B valid dan reliabel sebagai alat ukur apresiasi humor dan tidak mengalami bias gender. Artinya, tidak ada perbedaan apresiasi terhadap SKH antara subjek laki-laki dan perempuan.

Beberapa faktor yang mempengaruhi kepekaan humor diantaranya adalah pengetahuan, latar belakang sosial-budaya, tipe kepribadian, keadaan gangguan jiwa tertentu, dan kedewasaan. Dengan demikian alat tes yang baik memiliki sifat terbuka terhadap semua budaya karena terdapat keprihatinan yang luas menyangkut kemampuan penerapan tes-tes yang tersedia untuk orang-orang yang tidak diuntungkan dari segi budaya (Sarwono, 2005). Hasil tes sangat tergantung pada kebudayaan seseorang dibesarkan, tiap budaya memperkuat perkembangan perilaku yang diadaptasikan pada nilai budaya atau subbudaya yang lain dari budaya asal seseorang dibesarkan (Anastasi \& Urbina, 2007). Secara tradisional, pengembangan tes-tes psikologi lintas budaya telah berusaha menyingkirkan satu atau lebih parameter yang bermuatan perbedaan antara satu budaya dengan budaya lainnya, salah satunya yaitu penggunaan bahasa (Anastasi \& Urbina, 2007). SKH berisi aitemaitem figural (berupa gambar kartun) tanpa unsur kata dalam bahasa apapun, sehingga asumsinya terbuka untuk direspon oleh semua orang dengan latarbelakang budaya apapun.

Bangsa Indonesia terdiri dari 500 etnis sedangkan penelitian tentang humor adalah penelitian fenomena perilaku individu yang dipengaruhi oleh latar belakang budaya (Melalatoa, 1995), oleh karena itu peneliti berasumsi bahwa sangat beralasan jika pengujian reliabilitas SKH memasukkan unsur variabel etnis. Di dalam SP2010 (www.bps.go.id, 2015) tersedia 1331 kategori suku yang merupakan kode untuk nama suku, nama lain/alias suatu suku, nama subsuku, bahkan nama sub dari subsuku. Imbasnya, untuk menganalisis suku kerap diperlukan pengelompokan/klasifikasi ulang. Kerja sama BPS dengan Institute of South East Asian Studies (ISEAS) pada tahun 2013 menghasilkan klasifikasi baru yang dapat digunakan untuk menganalisis data suku SP2010. Selanjutnya telah dilakukan identifikasi mana saja kode yang merupakan nama lain, subsuku, dan sub-sub suku. Dihasilkan 633 kelompok suku besar dari kode suku yang tersedia dalam SP2010. Pengelompokan suku dilakukan berdasar literatur seperti buku ensiklopedi suku maupun dari pengetahuan para jejaring yang tersebar di seluruh Nusantara. Berdasar data SP2010, ratusan suku yang ada di Indonesia memiliki jumlah penduduk yang tidak sepadan. Suku Jawa adalah suku terbesar dengan proporsi 40,05 persen dari jumlah penduduk Indonesia. Menempati posisi kedua adalah Suku Sunda sebesar 15,50 persen. Selanjutnya suku-suku lainnya memiliki proporsi di bawah lima persen penduduk Indonesia (www.bps.go.id, 2015) (gambar 1).

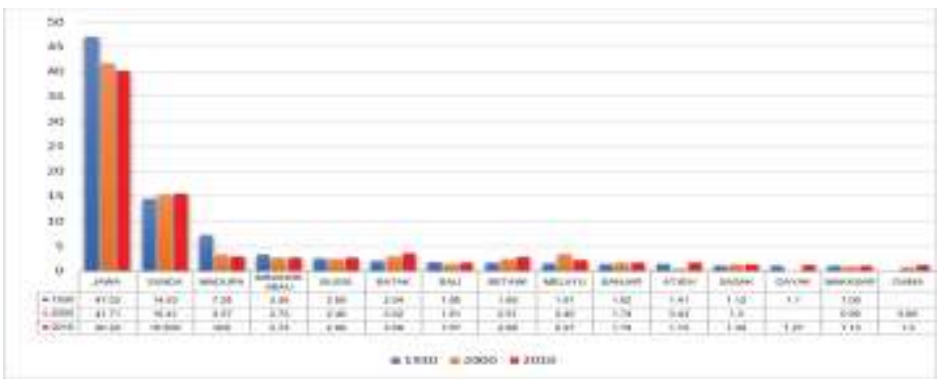

Gambar 1. Statistik jumlah penduduk Indonesia 
Komposisi sebaran etnis di Indonesia sejak tahun 1930 (sensus penduduk pertama kali di Indonesia) hingga tahun 2000 (dalam persentase) menunjukkan bahwa etnis Jawa, Sunda dan Madura adalah etnis yang dominan. Data hasil sensus tahun 2010 menunjukkan penurunan persentase etnis Madura. Kerusuhan etnis antara Madura dan Dayak yang terjadi di Pulau Kalimantan, berdampak berkurangnya data jumlah penduduk etnis Madura di Indonesia. Kejadian traumatis tersebut diperkirakan berpengaruh terhadap pengakuan identitas etnis saat dilakukan sensus, banyak orang Madura yang menjawab bukan orang Madura saat dilakukan sensus demi menjaga keamanan diri mereka. Hal lain yang berhubungan dengan penurunan etnis Madura adalah keberhasilan program KB (Pitoyo \& Triwahyudi, 2017).

Berdasarkan hasil Sensus Penduduk 2010, jumlah penduduk Indonesia adalah 237.556.363 orang, yang terdiri dari 119.507 .508 laki-laki dan 118.048 .783 perempuan. Pulau Jawa memiliki persentase 57,49 \% dari total penduduk seluruh Indonesia. Provinsi Jawa Barat, Jawa Timur dan Jawa Tengah dinyatakan sebagai provinsi berpenduduk paling banyak diantara provinsi lain yaitu sebesar 43.021.826, 37.476.011 dan 32.380.687 jiwa. Data tersebut menunjukkan bahwa sebaran mayoritas penduduk etnis Jawa berada di Pulau Jawa khususnya Jawa Timur dan Jawa Tengah serta Daerah Istimewa Yogyakarta (DIY) dengan jumlah penduduk sebanyak 3.453.158 jiwa dengan proporsi 1.705.896 laki-laki dan 1.747.262 perempuan serta memiliki kepadatan penduduk sebesar 1.084 jiwa per $\mathrm{km}^{2}$. Data tersebut menunjukkan bahwa DIY tidak termasuk dalam provinsi dengan jumlah penduduk terbesar akan tetapi mayoritas penduduknya adalah etnis Jawa (www.bps.go.id, 2015)

Berdasarkan data referensi tersebut di atas, penelitian ini bertujuan mendapatkan data empiris untuk menguatkan ke arah capaian jangka panjang, bahwa SKH menjadi tes adil budaya Indonesia. Selain itu, tes SKH diharapkan dapat digunakan menjadi salah satu alat ukur kepekaan humor pada kalangan yang lebih luas, khsusunya masyarakat Indonesia. Pada kajian ini selain pengujian reliabilitas SKH pada tiga etnis sekaligus, selanjutnya akan diuji apresiasi subjek laki-laki dan perempuan dari etnis Jawa, Sunda dan Madura terhadap SKH.

\section{Metode}

Sebanyak 300 subjek dipilih dari 615 responden mahasiswa etnis Jawa, Madura dan Sunda menggunakan kombinasi teknik stratified quota random sampling, yaitu mengambil 100 orang (50 laki-laki dan 50 perempuan) dari masing-masing etnis seperti pada tabel 1.

Tabel 1.

Data Populasi dan Sampel Penelitian

\begin{tabular}{lllllll}
\hline \multirow{2}{*}{ Etnis } & \multicolumn{4}{c}{ Populasi } & \multicolumn{2}{c}{ Sampel } \\
\cline { 2 - 7 } & $\boldsymbol{L}$ & $\boldsymbol{P}$ & Jumlah & $\boldsymbol{L}$ & $\boldsymbol{P}$ & Jumlah \\
\hline Jawa & 111 & 100 & 211 & 50 & 50 & 100 \\
Madura & 110 & 90 & 200 & 50 & 50 & 100 \\
Sunda & 107 & 97 & 204 & 50 & 50 & 100 \\
Total & 328 & 287 & 615 & 150 & 150 & 300 \\
\hline
\end{tabular}

Pengumpulan data penelitian menggunakan Skala Kepekaan Humor (SKH) dengan format respon tingkat kelucuan dalam lima pilihan mulai dari skor 1 (sangat tidak lucu) sampai skor 5 (sangat lucu). Berikut contoh aitem SKH versi A dan versi B, pada gambar 2 .

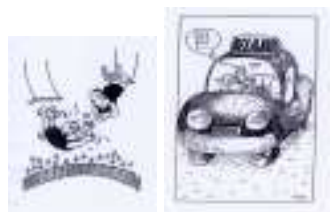

Gambar 2. Skala kepekaan humor 
Bauman (dalam www.bps.go.id, 2015) menyatakan bahwa sulit untuk mendefinisikan suku. Pada umumnya, seseorang mengidentifikasi dirinya pada suku tertentu berdasar keturunan. Penelitian ini menggunakan validitas isi tipe logical validity. Estimasi reliabilitas SKH menggunakan pendekatan metode penyajian tunggal (single trial administration) dan perhitungan koefisien reliabilitas SKH menggunakan formula alpha (Cronbach). Perbedaan apresiasi laki-laki dan perempuan etnis Jawa, Sunda dan Madura terhadap SKH diuji menggunakan Anava Dua Jalur.

\section{Hasil}

Koefisien reliabilitas (alpha) SKH sebesar 0,961 dengan tingkat mortalitas aitem 0\% (tidak ada aitem yang gugur), rentang indeks daya diskriminasi aitem (rit) terendah 0,390 (aitem nomor 6) dan tertinggi 0,568 (aitem nomor 68). Hasil analisis tersebut memberikan informasi atribut psikometris SKH, yaitu aitem-aitem SKH merepresentasikan domain ukurnya (logical validity), aitem-aitem SKH memiliki daya diskriminasi yang cukup tinggi dan reliabilitas SKH memadai sebagai alat ukur. Adapun kategorisasi dari skor perolehan SKH dapat dilihat pada tabel 2.

Tabel 2.

Kategorisasi Berdasarkan Skor Hipotetik SKH

\begin{tabular}{lllll}
\hline SKH & & Interval & Kategori & Skor \\
\hline S aitem & 76 & $319-380$ & Sangat Lucu & 5 \\
Xt & 380 & $258-318$ & Lucu & 4 \\
Xr & 76 & $198-257$ & Cukup Lucu & 3 \\
$\mu$ & 228 & $137-197$ & Tidak Lucu & 2 \\
$\sigma$ & 50,667 & $76-136$ & Sangat Tidak Lucu & 1 \\
\hline
\end{tabular}

$\mathrm{Xt}=$ skor tertinggi, $\mathrm{Xr}=$ skor terendah, $\mu=$ rerata, $\sigma=$ deviasi standar

Indeks normalitas sebaran data apresiasi terhadap SKH diperoleh dari KS-Z=0,478; $p=0,976(p>0,05)$, artinya sebaran data sampel normal sehingga sampel merepresentasikan populasinya. Indeks homogenitas varians skor ditunjukkan dengan Levene's Test $\mathrm{F}=1,171$; $\mathrm{p}=0,119(\mathrm{p}>0,05)$ artinya kelompok jenis kelamin dan kelompok etnis memiliki variansi skor yang setara (homogen). Dengan demikian data apresiasi terhadap SKH pada masing-masing kelompok tersebut layak dilakukan uji komparasi, seperti yang tampak pada tabel 3 berikut ini.

Tabel 3.

Hasil Uji Perbedaan Apresiasi terhadap SKH antar Etnis-antar Jenis Kelamin

\begin{tabular}{llllll}
\hline Source & $\begin{array}{l}\text { Type III Sum of } \\
\text { Squares }\end{array}$ & df & Mean Square & F & \multirow{2}{*}{ Sig. } \\
\hline Corrected Model & 29396,627 & 5 & 5879,325 & 3,460 &, 005 \\
Intercept & 17889115,213 & 1 & 17889115,213 & 10526,923 &, 000 \\
JK & 3227,520 & 1 & 3227,520 & 1,899 &, 169 \\
ETNIS & 16398,887 & 2 & 8199,443 & 4,825 &, 009 \\
JK ${ }^{*}$ ETNIS & 9770,220 & 2 & 4885,110 & 2,875 &, 058 \\
Error & 499614,160 & 294 & 1699,368 & & \\
Total & 18418126,000 & 300 & & & \\
Corrected Total & 529010,787 & 299 & & & \\
\hline
\end{tabular}


Berdasarkan tabel 3, dapat dijelaskan bahwa:

1. Corrected model signifikan $(\mathrm{p}<0,05)$ menunjukkan bahwa pengaruh variabel jenis kelamin dan variabel etnis secara terpisah maupun bersama-sama terhadap apresiasi SKH adalah model yang valid.

2. Intercept signifikan $(\mathrm{p}<0,05)$ menunjukkan bahwa apresiasi terhadap SKH dapat berubah tanpa ada pengaruh dari variabel jenis kelamin dan variabel etnis.

3. Pengaruh jenis kelamin terhadap apresiasi SKH di dalam model, tidak signifikan $(p<0,169)$. Laki-laki dan perempuan menunjukkan apresiasi yang relatif setara terhadap SKH

4. Pengaruh etnis terhadap apresiasi SKH di dalam model, signifikan $(\mathrm{p}<0,05)$. Antar etnis menunjukkan perbedaan apresiasi yang signifikan terhadap SKH.

5. Pengaruh interaksi antara jenis kelamin dan etnis terhadap apresiasi SKH, tidak signifikan $(p>0,05)$. Apresiasi terhadap SKH tidak dipengaruhi oleh interaksi antara variabel etnis dan variabel jenis kelamin

6. $\mathrm{R}^{2}=0,056$ menunjukkan nilai determinasi variabel jenis kelamin dan etnis terhadap apresiasi SKH sangat lemah (mendekati 0), artinya korelasinya lemah.

Ketidaksejaaran garis di dalam diagram di bawah ini memberikan gambaran indikasi adanya efek interaksi antar etnis terhadap apresiasi SKH, seperti pada gambar 3 berikut.

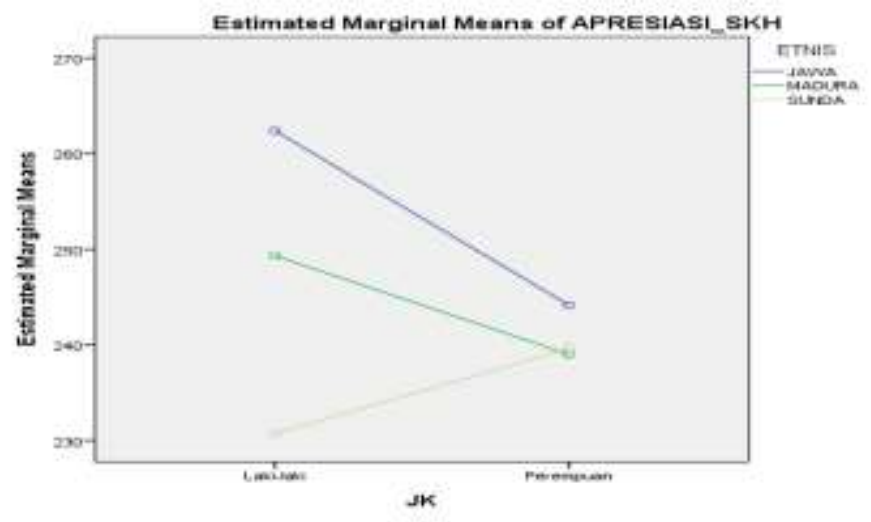

Gambar 3. Diagram Plot Mean setelah Uji Anava

Post hoc test untuk variabel etnis menunjukkan antara orang Jawa dan Madura $(p>0,05)$ maupun antara orang Madura dan Sunda $(p>0,05)$ memiliki apresiasi yang relatif sama terhadap SKH (tabel 4). Perbedaan apresiasi terhadap SKH terbaca signifikan antara orang Jawa dan orang Sunda $(\mathrm{p}<0,05)$, secara umum orang Jawa lebih apresiatif terhadap SKH daripada orang Sunda.

Tabel 4.

Multiple Comparisons Post hoc test Apresiasi SKH antara Etnis Jawa, Madura, Sunda

\begin{tabular}{lllllll}
\hline \multirow{2}{*}{ (I) Etnis } & U) Etnis & $\begin{array}{l}\text { Mean Difference } \\
\text { (I-J) }\end{array}$ & \multicolumn{2}{c}{ Std. Error } & Sig. & \multicolumn{2}{l}{$\begin{array}{l}\text { 95\% Confidence Interval } \\
\text { Lower Bound }\end{array}$} & Upper Bound \\
\hline Jawa & Madura & 9,12 & 5,830 &, 263 & $-4,61$ & 22,85 \\
& Sunda & $18,11^{*}$ & 5,830 &, 006 & 4,38 & 31,84 \\
\multirow{3}{*}{ Madura } & Jawa & $-9,12$ & 5,830 &, 263 & $-22,85$ & 4,61 \\
& Sunda & 8,99 & 5,830 &, 273 & $-4,74$ & 22,72 \\
& Jawa & $-18,11^{*}$ & 5,830 &, 006 & $-31,84$ & $-4,38$ \\
& Madura & $-8,99$ & 5,830 &, 273 & $-22,72$ & 4,74 \\
\hline
\end{tabular}

Perbedaan apresiasi SKH antara orang Jawa dan orang Sunda akan diuraikan lebih detil 
pada tiap komponen SKH (tabel 5). Levene's statistic sebesar 3,251 dengan $\mathrm{p}=0,040(\mathrm{p}<0,05)$ menunjukkan ketidaksetaraan variansi skor apresiasi terhadap komponen kekerasan SKH antara orang Jawa, Madura dan Sunda. Asumsi homogenitas varians skor tidak terpenuhi, dengan demikian data apresiasi terhadap komponen Kekerasan SKH pada variabel etnis tidak layak untuk uji komparasi.

Tabel 5.

Kategorisasi dan Distribusi Subjek Berdasarkan Skor Empirik SKH

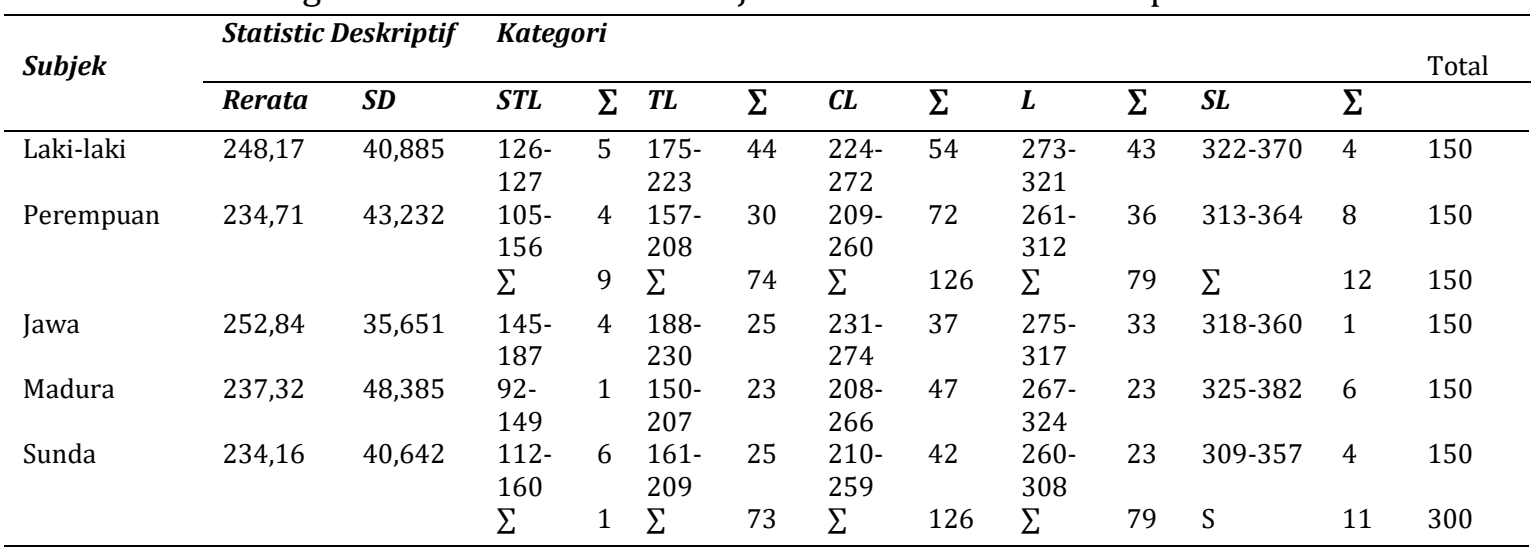

STL: Sangat Tidak lucu, TL: Tidak Lucu, CL: Cukup Lucu, L: Lucu, SL: Sangat Lucu

Levene's statistic sebesar 5,102 dengan $\mathrm{p}=0,007(\mathrm{p}<0,05)$ menunjukkan ketidaksetaraan variansi skor apresiasi terhadap komponen kekesalan SKH antara orang Jawa, Madura dan Sunda. Asumsi homogenitas varians skor tidak terpenuhi, dengan demikian data apresiasi terhadap komponen Kekesalan SKH pada variabel etnis tidak layak untuk uji komparasi. Levene's statistic sebesar 1,175 dengan $\mathrm{p}=0,310(\mathrm{p}>0,05)$ menunjukkan kesetaraan variansi skor apresiasi terhadap komponen parodi SKH antara orang Jawa, Madura dan Sunda. Asumsi homogenitas varians skor terpenuhi, dengan demikian data apresiasi terhadap komponen Parodi SKH pada variabel etnis layak uji komparasi (tabel 6).

Tabel 6.

Data Statistik Deskriptif Apresiasi Komponen Parodi SKH pada Etnis Jawa, Madura dan Sunda

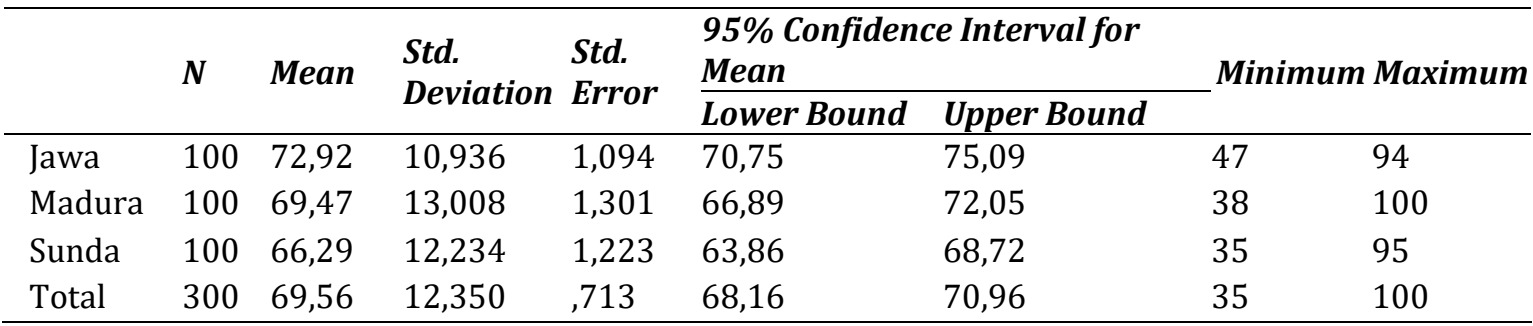

Indeks perbedaan sebesar $\mathrm{F}=7,523$ dengan $\mathrm{p}=0,001(\mathrm{p}<0,01)$ menunjukkan perbedaan apresiasi yang sangat signifikan terhadap komponen Parodi SKH antara etnis Jawa, Madura dan Sunda (tabel 7).

Tabel 7.

Perbedaan Apresiasi Komponen Parodi SKH antara Etnis Jawa, Madura dan Sunda

\begin{tabular}{llllll}
\hline & Sum of Squares & df & Mean Square & $\boldsymbol{F}$ & Sig. \\
\hline Between Groups & 2199,060 & 2 & 1099,530 & 7,523 &, 001 \\
Within Groups & 43406,860 & 297 & 146,151 & & \\
Total & 45605,920 & 299 & & & \\
\hline
\end{tabular}


Hasil post hoc test (tabel 8) menunjukkan antara etnis Jawa dan Madura $(\mathrm{p}>0,05)$ maupun etnis Madura dan Sunda $(p>0,05)$ memiliki apresiasi yang relatif sama terhadap komponen Parodi SKH.

Tabel 8.

Post hoc test Apresiasi Komponen Parodi SKH antara Etnis Jawa, Madura, Sunda

\begin{tabular}{lllllll}
\hline \multirow{2}{*}{ (I) Etnis } & (J) Etnis & \multirow{2}{*}{ Mean Difference (I-J) } & Std. Error & Sig. & \multicolumn{2}{c}{ 95\% Confidence Interval } \\
\hline Jawa & Madura & 3,450 & 1,710 &, 110 &,- 58 & 7,48 \\
& Sunda & $6,630^{*}$ & 1,710 &, 000 & 2,60 & 10,66 \\
\multirow{2}{*}{ Madura } & Jawa & $-3,450$ & 1,710 &, 110 & $-7,48$ &, 58 \\
& Sunda & 3,180 & 1,710 &, 152 &,- 85 & 7,21 \\
\multirow{2}{*}{ Sunda } & Jawa & $-6,630^{*}$ & 1,710 &, 000 & $-10,66$ & $-2,60$ \\
& Madura & $-3,180$ & 1,710 &, 152 & $-7,21$ &, 85 \\
\hline
\end{tabular}

Perbedaan apresiasi terhadap komponen Parodi terbaca sangat signifikan antara etnis Jawa dan Sunda, orang Jawa lebih apresiatif terhadap komponen Parodi daripada orang Sunda. Levene's statistic sebesar 1,028 dengan $\mathrm{p}=0,359(\mathrm{p}>0,05)$ menunjukkan kesetaraan variansi skor apresiasi terhadap komponen kreativitas SKH antara orang Jawa, Madura dan Sunda. Asumsi homogenitas varians skor terpenuhi, dengan demikian data pada variabel etnis layak untuk uji komparasi.

Tabel 9.

Statistik Deskriptif Apresiasi Komponen Kreativitas SKH pada Etnis Jawa, Madura dan Sunda

\begin{tabular}{|c|c|c|c|c|c|c|c|c|}
\hline & \multirow{2}{*}{$N$} & \multirow{2}{*}{ Mean } & \multirow{2}{*}{$\begin{array}{l}\text { Std. } \\
\text { Deviation }\end{array}$} & \multirow{2}{*}{$\begin{array}{l}\text { Std. } \\
\text { Error }\end{array}$} & \multicolumn{2}{|c|}{ 95\% Confidence Interval for Mean } & \multirow[t]{2}{*}{ Min } & \multirow[t]{2}{*}{$\operatorname{Max}$} \\
\hline & & & & & Lower Bound & Upper Bound & & \\
\hline Jawa & 100 & 48,89 & 9,023 & ,902 & 47,10 & 50,68 & 27 & 66 \\
\hline Madura & 100 & 47,13 & 9,524 & ,952 & 45,24 & 49,02 & 28 & 70 \\
\hline Sunda & 100 & 45,15 & 8,702 & 870 & 43,42 & 46,88 & 22 & 67 \\
\hline Total & 300 & 47,06 & 9,187 &, 530 & 46,01 & 48,10 & 22 & 70 \\
\hline
\end{tabular}

Indeks perbedaan sebesar $\mathrm{F}=4,238$ dengan $\mathrm{p}=0,015(\mathrm{p}<0,05)$ menunjukkan perbedaan apresiasi yang signifikan terhadap komponen Kreativitas SKH antara etnis Jawa, Madura dan Sunda, seperti yang terlihat pada tabel 10 berikut.

Tabel 10.

Perbedaan Apresiasi Komponen Kreativitas SKH Etnis Jawa, Madura dan Sunda

\begin{tabular}{llllll}
\hline & Sum of Squares & df & Mean Square & F & Sig. \\
\hline Between Groups & 700,187 & 2 & 350,093 & 4,238 &, 015 \\
Within Groups & 24535,850 & 297 & 82,612 & & \\
Total & 25236,037 & 299 & & & \\
\hline
\end{tabular}

Post hoc test berdasarkan tabel 11 menunjukkan antara etnis Jawa dan Madura $(\mathrm{p}>0,05)$, etnis Madura dan Sunda $(p>0,05)$ memiliki apresiasi yang relatif sama terhadap komponen Kreativitas SKH. 
Tabel 11.

Post hoc test Apresiasi Komponen Kreativitas SKH Etnis Jawa, Madura, Sunda

\begin{tabular}{lllllll}
\hline \multirow{2}{*}{ (I) Etnis } & \multirow{2}{*}{ J) Etnis } & $\begin{array}{l}\text { Mean Difference } \\
\text { (I-J) }\end{array}$ & $\begin{array}{l}\text { Std. } \\
\text { Error }\end{array}$ & Sig. & \multicolumn{2}{c}{ 95\% Confidence Interval } \\
Lower Bound & Upper Bound \\
\hline Jawa & Madura & 1,760 & 1,285 &, 358 & $-1,27$ & 4,79 \\
& Sunda & $3,740^{*}$ & 1,285 &, 011 &, 71 & 6,77 \\
\multirow{2}{*}{ Madura } & Jawa & $-1,760$ & 1,285 &, 358 & $-4,79$ & 1,27 \\
& Sunda & 1,980 & 1,285 &, 274 & $-1,05$ & 5,01 \\
& Jawa & $-3,740^{*}$ & 1,285 &, 011 & $-6,77$ &,- 71 \\
& Madura & $-1,980$ & 1,285 &, 274 & $-5,01$ & 1,05 \\
\hline
\end{tabular}

Perbedaan apresiasi terhadap komponen kreativitas SKH terbaca signifikan antara etnis Jawa dan Sunda, orang Jawa lebih apresiatif daripada orang Sunda, seperti terlihat pada tabel 12 berikut.

Tabel 12.

Distribusi Subjek Etnis Jawa dan Sunda Berdasarkan Apresiasi Komponen Parodi dan Kreativitas SKH

\begin{tabular}{lllllll}
\hline \multirow{2}{*}{ Kategori } & Parodi & Jawa & Sunda & Kreativitas & Jawa & Sunda \\
\cline { 2 - 7 } & Interval & $\boldsymbol{f}$ & $\boldsymbol{f}$ & Interval & $\boldsymbol{f}$ & $\boldsymbol{f}$ \\
\hline SL & $88-105$ & 6 & 3 & $63-75$ & 4 & 1 \\
L & $71-87$ & 52 & 38 & $52-62$ & 42 & 24 \\
CL & $55-70$ & 35 & 42 & $39-50$ & 42 & 55 \\
TL & $38-54$ & 7 & 16 & $27-38$ & 12 & 17 \\
STL & $21-37$ & 0 & 1 & $15-26$ & 0 & 3 \\
& S & 100 & 100 & S & 100 & 100 \\
\hline
\end{tabular}

STL: Sangat Tidak Lucu, TL: Tidak Lucu, CL: Cukup Lucu, L: Lucu, SL: Sangat Lucu

Perbedaan apresiasi terhadap aitem-aitem komponen parodi dan kreativitas SKH antara subjek etnis Jawa dan Sunda tersaji dalam tabel 12 di atas. Sangat menonjol kecenderungan apresiasi mayoritas subjek kedua etnis pada kategori "cukup lucu" dan "lucu".

\section{Pembahasan}

Hasil uji komparasi menunjukkan bahwa antara laki-laki dan perempuan etnis Jawa, Madura dan Sunda memiliki apresiasi yang setara terhadap materi humor dalam aitem-aitem SKH, yaitu pada taraf cukup lucu. Antar etnis menunjukkan perbedaan apresiasi terhadap SKH, sedangkan antara laki-laki dan perempuan menunjukkan apresiasi yang relatif setara terhadap SKH, yaitu pada taraf cukup lucu. Secara umum dapat disimpulkan bahwa pengaruh variabel etnis terhadap apresiasi SKH tidak bergantung pada jenis kelamin. Hasil penelitian ini memberikan data empirik bahwa variabel jenis kelamin tidak mempengaruhi apresiasi terhadap SKH, subjek laki-laki dan perempuan dalam penelitian ini memiliki apresiasi yang relatif sama terhadap aitem-aitem SKH, yaitu "cukup lucu". Stimulus dalam aitem SKH yang dinilai lucu oleh kelompok subjek laki-laki dari etnis manapun diantara etnis Jawa, Madura dan Sunda dinilai lucu juga oleh kelompok subjek perempuan dari etnis manapun diantara etnis Jawa, Sunda dan Madura. Secara terpisah beberapa penelitian sebelumnya menguji perbedaan apresiasi laki-laki dan perempuan terhadap SKH pada etnis Jawa (Triyantoro, 2014), pada etnis Madura (Yusnita, 2014) dan pada etnis Sunda (Kusumasakti, 2014). Ketiga penelitian tersebut menunjukkan hasil yang sama yaitu tidak ada perbedaan apresiasi terhadap SKH antara laki-laki dan perempuan pada masing-masing etnis tersebut, sejalan juga dengan penelitian sebelumnya oleh Utomo (2006).

Anggapan bahwa perempuan kurang lucu daripada pria adalah stereotip. Salah satu 
mekanisme untuk mempertahankan dan mendukung stereotip adalah tekanan nilai-nilai terhadap stereotip, jika tekanan tersebut dialami atau dirasakan oleh kaum perempuan dalam konteks humor maka kemungkinan perempuan akan merasa kurang lucu daripada laki-laki. Perempuan yang meyakini bahwa mereka tidak lucu atau humor mereka tidak diterima dengan baik mungkin akan merasa terhambat dalam unjuk kualitas diri di berbagai bidang seperti pendidikan (Goodboy et al. dalam Hooper dkk., 2016), kesehatan mental (Berk; Crawford \& Caltabiano, Tucker et al., dalam Hooper dkk., 2016), dan lain sebagainya.

Hasil analisis lanjutan (post hoc test) pasca Anava menunjukkan data bahwa perbedaan apresiasi terhadap SKH pada etnis Jawa, Madura dan Sunda khusus antara subjek etnis Jawa dan Sunda. Lebih khusus lagi perbedaan apresiasi terhadap dua dari empat komponen SKH yaitu komponen parodi dan kreativitas. Subjek etnis Jawa lebih apresiatif daripada subjek etnis Sunda terhadap komponen parodi maupun kreativitas.

Parodi adalah karya sastra atau seni yang dengan sengaja menirukan gaya, kata penulis, atau pencipta lain dengan maksud mencari efek kejenakaan, sedangkan kreativitas adalah daya cipta, perihal berkreasi, kekreatifan (https://kbbi.web.id/parodi, https://kbbi.web.id/ kreativitas, 2020). Menurut O'Connel (dalam Utomo, 2006) kepekaan humor seseorang diindikasikan dari kemampuan mengubah persepsi kognitif secara cepat, memandang masalah dari perspektif yang berbeda yakni dari segi kelucuannya untuk menjauhkan diri dari ancaman situasi bermasalah, mengurangi perasaan cemas dan tidak berdaya. Oleh karena itu dalam konteks humor kreativitas dapat diartikan sebagai suatu pola pikir atau ide yang timbul secara spontan, imajinatif, baru dan segar yang memberi efek kelucuan.

Berdasarkan penelusuran data statistik deskriptif nampak bahwa sebagian besar subjek etnis Jawa dan Sunda memiliki apresiasi terhadap komponen parodi dan kreativitas SKH pada kategori yang sama yaitu "cukup lucu" dan "lucu", perbedaan antara keduanya terletak pada jumlah subjek di dalam dua kategori dominan tersebut. Dengan demikian dapat dijelaskan bahwa perbedaan apresiasi terhadap SKH antara subjek etnis Jawa dan Sunda dalam penelitian ini tidak mengubah dan tidak berpengaruh terhadap kecenderungan apresiasi bahwa aitem-aitem SKH "cukup lucu" dan "lucu".

Hasil tes seseorang sangat tergantung pada kebudayaan seseorang itu dibesarkan, tiap budaya memperkuat perkembangan perilaku yang diadaptasikan pada nilai budaya atau sub budaya yang lain dari budaya asal seseorang dibesarkan (Anastasi \& Urbina, 2007). Beberapa faktor yang mempengaruhi kepekaan humor seseorang, yakni a) pengetahuan, b) latar belakang sosial-budaya, c) tipe kepribadian, d) keadaan gangguan jiwa tertentu dan e) kedewasaan, sehingga suatu alat tes yang baik memiliki sifat adil dan terbuka terhadap semua budaya karena terdapat keprihatinan yang luas menyangkut kemampuan penerapan tes-tes yang tersedia untuk orang-orang yang tidak diuntungkan dari segi budaya (Sarwono, 2005). Hasil analisis lanjutan untuk melihat perbedaan apresiasi terhadap dua komponen SKH antara subjek berlatarbelakang etnis Jawa dan Sunda menunjukkan bahwa latarbelakang budaya tidak mempengaruhi apresiasi terhadap SKH, aitem-aitem SKH dinilai "cukup lucu" dan "lucu" oleh sebagian besar subjek kedua etnis tersebut.

Pengujian terhadap SKH masih perlu dilakukan lagi untuk tujuan jangka panjang capaian SKH menjadi tes adil budaya (culture fair test) Indonesia. Kutipan dari pernyataan Martin dan Ford (dalam Jiang dkk., 2019) berikut ini menjadi motivasi melanjutkan studi yang lebih komprehensif terhadap SKH: "humor adalah aktivitas universal yang dialami manusia dalam kehidupan sehari-hari dan dalam segala macam konteks sosial. Orang dari latar belakang budaya yang berbeda dapat memahami humor dengan cara yang berbeda, artinya ada pengaruh penting dari budaya pada cara humor digunakan dan situasi yang dianggap pantas untuk tertawa."

\section{Simpulan}

Berdasarkan hasil penelitian dapat dinyatakan bahwa SKH valid dan reliabel sebagai alat ukur kepekaan humor. SKH juga memiliki data empiris yang mendukungnya menjadi tes yang 
adil budaya (culture fair) Indonesia. Selanjutnya materi humor di dalam aitem-aitem SKH tergolong "cukup lucu" dan "lucu". Dengan demikian, SKH dapat digunakan menjadi salah satu alat ukur kepekaan humor pada kalangan yang lebih luas.

\section{DAFTAR PUSTAKA}

Abdullah, A. I. (2014). Validitas dan reliabilitas skala kepekaan humor (SKH) versi a-b pada mahasiswa Etnis Bugis. Skripsi (tidak diterbitkan). Yogyakarta: Fakultas Psikologi Universitas Ahmad Dahlan.

Anastasi, A., \& Urbina, S. (2007). Tes psikologi (edisi ke-7). Jakarta: Indeks.

Bastaman, H. D. (2007). Logoterapi: Psikologi untuk menemukan makna hidup dan meraih hidup bermakna. Jakarta: PT Raja Grafindo Persada.

Borcherdt, B. (2002). Humor and its contributions to mental health. Journal of RationalEmotive \& Cognitive-Behavior Therapy, 20, 247-257. http://dx.doi.org/10.1023/ A:1021168527963

Colom, G. G., Alcover, C.T., Sánchez-Curto, C. \& Zárate-Osuna, J. (2011). Study of the effect of positive humour as a variable that reduces stress: Relationship of humour with personality and performance variables. Psychology in Spain, Vol. 15, No. 1, 9-21.

Garner, R. L. (2006). Humor in pedagogy: How ha-ha can lead to aha! College Teaching, 54, 177- 180. http://dx.doi.org/10.3200/CTCH.54.1.177-180

Hackathorn, J., Garczynski, A. M., Blankmeyer, K., Tennial, R. D., \& Solomon, E. D. (2012). All kidding aside: Humor increases learning at knowledge and comprehension levels. Journal of Scholarship of Teaching and Learning, 11, 116-123.

Hasanat, N. U \& Subandi. (1998). Pengembangan alat kepekaan terhadap humor. Jurnal Psikologi, No. 1, 17-25.

Hooper, J., Sharpe, D. \& Roberts, S. G. B. (2016). Are men funnier than women, or do we just think they are? Translational Issue in Psychological Science, Vol. 2, No. 1, 54-62.

Jiang, T., Li, H. \& Hou, Y. (2019). Cultural differences in humor perception, usage and implication. Front. Psychology. https://doi.org/10.3389/fpsyg.2019.00123

Https://kbbi.web.id/parodi, https://kbbi.web.id/kreativitas, diakses pada 11 Juli 2020.

Koentjaraningrat. (1999). Manusia dan kebudayaan di Indonesia. Jakarta: Djambatan.

Kusumasakti, W. (2014). Validitas dan reliabilitas skala kepekaan humor (SKH) versi a-b pada mahasiswa Etnis Sunda. Skripsi (tidak diterbitkan). Yogyakarta: Fakultas Psikologi Universitas Ahmad Dahlan.

Levine, J. (1956). Responses to humor. Scientific American, 194(2), 31-35.

Martin, R. A., \& Lefcourt, H. M. (1984). Situational humor response questionnaire: Quantitative measure of sense of humor. Journal of Personality and Social Psychology, 47(1), 145-155.

Martin, R.A. dan Lefcourt, H. (1983). Sense of humor as a moderator between stressors and moods. Journal of Personality and Social Psychology 45(6):1313-1324

McGhee, Paul E. and Theodora Panoutsopoulou. (1990). The role of cognitive factors in children's metaphor and humor comprehension. HUMOR: International Journal of Humor Research, Vol. 3:4, pp. 379-402.

Melalatoa, M. J. (1995). Ensiklopedi suku bangsa di Indonesia. Jakarta: Departemen Pendidikan dan Kebudayaan RI.

Nilsen, D. L. F. (1993). Humor scholarship: A research bibliography. London: Greenwood Press

Parianti, Y. (2014). Validitas dan reliabilitas skala kepekaan humor (SKH) versi a-b pada mahasiswa Etnis Sasak. Skripsi (tidak diterbitkan). Yogyakarta: Fakultas Psikologi Universitas Ahmad Dahlan.

Pitoyo, A. J. \& Triwahyudi, H. (2017). Dinamika perkembangan etnis di Indonesia dalam konteks persatuan negara. Populasi, vol. 25., No. 1, 64-81.

Sarwono, S., W. (2005). Psikologi dalam praktek (edisi revisi). Jakarta: Restu Agung 
Susanti, S. V. T. (2014). Validitas dan reliabilitas skala kepekaan humor (SKH) versi a-b pada mahasiswa Etnis Sambas. Skripsi (tidak diterbitkan). Yogyakarta: Fakultas Psikologi Universitas Ahmad Dahlan.

Triyantoro, D. B. (2014). Validitas dan reliabilitas skala kepekaan humor (SKH) versi a-b pada mahasiswa Etnis Jawa. Skripsi (tidak diterbitkan). Yogyakarta: Fakultas Psikologi Universitas Ahmad Dahlan.

Utomo, U. H. N. (2006). Validitas dan reliabilitas skala kepekaan terhadap humor. Tesis (tidak dipublikasikan). Yogyakarta: Universitas Gadjah Mada.

Utomo, U. H. N. \& Diponegoro, A.M. (2017). Appreciation towards the sense of humor scale based on gender and ethnicity. Presented at $3^{\text {rd }}$ Asean Conference in Psychology, Counseling and Humanities (AC-PCH 2017). Advances in Social Science, Education and Humanities Research, Vol. 33, 226-229. Atlantis Press.

www.bps.go.id. (2015, 25 November). Mengulik data suku di Indonesia. Diakses pada 4 Juni 2020, dari https://www.bps.go.id/news/2015/11/18/127/mengulik-data-suku-diindonesia.html

Yusnita, H. (2014). Validitas dan reliabilitas skala kepekaan humor (SKH) versi a-b pada mahasiswa Etnis Madura. Skripsi (tidak diterbitkan). Yogyakarta: Fakultas Psikologi Universitas Ahmad Dahlan. 